\title{
PENYELESAIAN KREDIT BERMASALAH PADA PT. BPR LUBUK RAYA MANDIRI PADANG
}

\author{
Bima Arya Pangestwo, Hj. Ratna Widayati \\ Akademi Keuangan Dan Perbankan "Pembangunan" Padang \\ Aryapangestwobima@gmail.com
}

\begin{abstract}
Credit implementation at PT. BPR Lubuk Raya Mandiri is quite good, as seen from the current credit collectibility which increased from 2013-2017 and non-performing loans decreased. The causes of non-performing loans caused by the economic downturn have caused the ability to repay principal payments and interest on loans that are experiencing problems so that they become substandard, doubtful and even bad. Non-performing loan settlement conducted by PT. BPR Lubuk Raya Mandiri has a policy on credit settlement by means of which the bank will give a warning in advance by telephone, otherwise the bank will send downs in the form of a warning letter to the debtor, if that is not ignored then the bank will take the decision to make a sale collateral or auctioning the collateral publicly in order to pay off debtor obligations to the bank.
\end{abstract}

Keywords: Settlement of Problem Loans

\section{PENDAHULUAN}

Perbankan merupakan sektor terpenting dalam laju perekonomian suatu negara, sebab dengan adanya perbankan pertumbuhan ekonomi suatu negara dapat meningkat, bahkan dalam kehidupan masyarakat sebagian besar melibatkan jasa dari perbankan. Tingkat kepercayaan masyarakat terhadap perbankan terus meningkat ditandai dengan adanya peningkatan dana masyarakat kesektor perbankan.

Sejalan dengan pesatnya pembangunan di Indonesia khususnya pembangunan ekonomi, maka lembaga keuangan seperti bank merupakan salah satu alat untuk membantu kelancaran ekonomi sebagai penyedia modal dalam bentuk pemberian kredit. Bank sebagai lembaga keuangan tidak pernah terlepas dari kredit sebab jumlah kredit yang disalurkan akan menentukan keuntungan bank. Kredit merupakan salah satu kegiatan bisnis perbankan yang memiliki resiko paling besar dan signifikan dari semua risiko yang mempengaruhi pendapatan bagi bank. Risiko kredit disini dimaksudkan sebagai ketidak mampuan debitur untuk melunasi kewajibannya kepada pihak bank (Rosmilia, 2009).

Semua jumlah kredit yang telah diberikan kepada para debitur menjadi pendapatan terbesar bagi bank. Debitur harus mampu mengembalikan pinjaman beserta bunganya sesuai dengan kesepakatan yang telah disetujui di awal pemberian kredit. Walaupun analisis kredit telah dilakukan oleh pihak bank, pada kenyataannya ketika kredit telah diberikan timbul berbagai macam persoalan yang 
disebabkan oleh berbagai faktor, yaitu faktor intenal dan eksternal. Persoalan yang timbul tersebut berpengaruh terhadap tingkat pengembalian atau kolektibilitas kredit sehingga dapat menyebabkan terjadinya kredit bermasalah (Desda \& Yurasti, 2019).

Kredit bermasalah adalah kondisi keuangan yang sering terjadi dilembaga keuangan terutama perbankan. Kredit bermasalah dapat di ukur dari tingkat kolektibilitasnya, yaitu persentase jumlah kredit bermasalah (dengan kriteria kurang lancar, diragukan dan macet) terhadap total kredit yang dikeluarkan bank. Kredit yang dikatakan bermasalah belum tentu dapat dikatakan kredit macet sedangkan untuk kredit macet sudah tentu menjadi kredit bermasalah (Savitri et al., 2014).

PT. Bank Perkreditan Rakyat (BPR) Lubuk Raya Mandiri Padang merupakan salah satu BPR yang masih aktif beroperasi di kota Padang, yang memberikan pelayanan jasa kepada masyarakat dalam berbagai bentuk. Salah satu pelayanan yang diberikan oleh bank tersebut adalah dalam bentuk pemberian fasilitas kredit. Peningkatan pemberian kredit oleh bank dapat meningkatkan laba yaitu berupa bunga atas pinjaman yang diberikan kepada nasabah, juga akan menaikan jumlah piutang pada bank, dengan naiknya jumlah kredit maka kemungkinan tidak tertagihnya kredit dan terjerat kedalam kredit bermasalah.

Berdasarkan uraisan diatas maka penulis tertarik untuk menuangkannya dalam bentuk Tugas Akhir dengan judul "Penyelesaian Kredit Bermasalah Pada Pt. Bpr Lubuk Raya Mandiri Padang".

\section{METODE PENELITIAN}

\section{Metode Pengumpulan Data}

Di dalam penelitian ini penulis menggunakan metode pengumpulan data dengan dua cara yaitu :

a. Studi Pustaka (Library Rrsearch)

Penelitian ini dilakukan dengan cara mempelajari buku-buku, artikel-artikel, bacaan laporan-laporan dan publikasi yang berhubungan dengan objek penelitian.

b. Studi Lapangan (Field Research)

Penelitian yang langsung dilakukan pada PT. Bank Perkreditan Rakyat Lubuk Raya Mandiri Padang untuk memperoleh data yang diperlukan dan melakukan wawancara untuk mendapatkan data.

\section{Metode Analisa Data}

Dalam menganalisa data, penulis menggunakan metode analisa kualitatif yaitu dengan menguraikan data secara sistematis dari fakta-fakta yang didapat kemudian dihubungkan dengan prosedur penyelesaian kredit bermasalah pada PT. Bank Perkrediran Rakyat Lubuk Raya Mandiri Padang.

\section{HASIL DAN PEMBAHASAN}

\section{Proses Pemberian Kredit}

Dalam proses memberian kredit yang dilakukan oleh PT. BPR Lubuk Raya Mandiri padang harus melalui proses pemberian kredit yang 
meliputi ketentuan dan syarat yang harus dilakukan sejak nasabah mengajukan permohonan kredit sampai tahap akhir. Kerena itu ada beberapa tahap proses pemberian kredit yang dilakukan oleh PT. BPR Lubuk Raya Mandiri kepada pihak calon debitur yaitu:

a. Permohonan Kredit

Pemberian kredit yang dilakukan oleh PT. BPR Lubuk Raya mandiri Padang didasarkan pada permohonan tertulis dari calon debitur berdasarkan data yang diperlukan oleh bank, disesuaikan dengan jenis nilai kredit dan identitas yang diberikan calon debitur yaitu:

1) Dokumen perizinan / surat keterangan usaha.

2) Laporan keuangan.

3) Laporan kredit nasabah apabila calon nasabah sebelumnya mendapat fasilitas pinjaman dari bank lain.

4) Copy dokumen / agunan.

\section{b. Analisis Kredit}

Setelah calon debitur mengajukan premohonan kredit dan diterima oleh bank, maka calon nasabah diminta untuk memberi keterangan yang dapat menjelaskan isi dari dokumen tersebut dan disampaikan kepada bank. Keterangan tersebut dilakukakn melalui wawancara oleh pihak bank. Selanjutnya, petugas bank melakukan analisis kredit berdasarkan pedoman yang sudah ditentukan di dalam bank.

Berikut yang dilakukan petugas bank dalam menganalisis calon nasabah untuk memastikan kesesuaian data dan kesesuaian fakta, diantaranya beberapa metode yang dilakukan petugas bank meliputi analisis dengan prinsip 5C yaitu:

1) Carakter (watak)

PT. BPR Lubuk Raya Mandiri menganalisis waktak calon debitur sebelum memberikan kredit, dalam menganalisis hal tersebut bank akan melihat dari latar belakang pekerjaan atau usaha calon nasabah itu apakah baik atau buruk kepribadiannya, dan bisa juga dengan metode cek riwayat kredit di Bank Indonsesia.

2) Capacity (kemampuan)

PT. BPR Lubuk Raya Mandiri juga melihat kemampuan calon nasabah dalam bidang usahanya dan penididikannya, apakah calon nasabah tersebut bisa memehasi ketentuan yang ada dalam pemerintah.

3) Capital (Modal)

PT. BPR Lubuk Raya Mandiri melihat kemampuan modal calon nasabahnya apakah efektif atau tidaknya yaitu dilihat dari laporan keuangannya.

4) Collateral (Agunan)

Kemampuan jaminan yang dilihat oleh PT. BPR Lubuk Raya Mandiri harus sesuai dengan kredit yang diajukan 
oleh nasabah karena nilai jaminan dibawah pengajuan kredit maka akan berdampak buruk apabila terjadi masalah pada kredit yang telah dicairkan oleh bank.

5) Conditian economy (Kondisi Ekonomi)

PT. BPR Lubuk Raya Mandiri menilai dari kondisi ekonomi dari calon debitur apakah prosepek dibidang usaha yang dimilikinya benar-benar baik, sehingga kemungkinan terjadinya kredit bermasalah semakin kecil terjadi.

\section{c. Keputusan Kredit}

Jika semua persyaratan calon debitur sudah lengkap, maka bank akan melakukan keputusan kredit diterima atau tidaknya pengajuan calon debitur dengan mengirim balasan dalam bentuk surat kepada calon debitur.

\section{d. Pencairan Kredit}

Setelah semua proses telah dilakukan oleh pihak calon debitur dan pengajuan pinjaman debitur disetujui, maka dana pinjaman tersebut akan diberikan secara tunai oleh pihak bank kepada calon debitur. Maka pihak bank akan melakukan akad kredit dengan calon debitur sebagai penerima kredit, akad kredit sebagai dasar persetujuan antara pihak bank dengan calon debitur akan syarat dan ketentuan dari kredit yang diajukan.

\section{e. Pengawasan Kredit.}

Dalam proses pemberian kredit diperlukan pengawasan kredit, pengawasan dari PT. BPR Lubuk Raya Mandiri tidak hanya dilakukan pada saat proses pemberian kredit tetapi juga dilakukan setelah kredit itu dicairkan. Pengawasan kredit ini dilakukan PT. BPR Lubuk Raya Mandiri secara langsung (aktif).

\section{Kolektibilitas Kredit / Kriteria Keadaan Kredit}

Kolektibilitas kredit merupakan status keadaan pembayaran angsuran bunga atau angsuran pokok dan bunga atau angsuran pokok dan bunga kredit oleh debitur serta tingkat kemungkinan diterimanya kembali dana yang ditanamkan dalam surat-surat berharga atau penanaman lainnya. Dalam pembayaran kembali kredit, terdapat dua dasar analisis debitur dalam pemberian kredit, yaitu kemauan membayar dan kemampuan membayar diaman untuk menentukan karakter calon debitur diperlukan peninjauan secara kuantitatif terhadap kualitas riwayat kredit calon debitur yang ditandai melalui pengecekan kolektibilitas.

table berikut:

Kolektibilitas kredit BPR Lubuk Raya Mandiri dapat dilihat dari 


\section{Tabel 1}

KOLEKTIBILITAS KREDIT

BANK PERKREDITAN RAKYAT LUBUK RAYA MANDIRI PADANG

\begin{tabular}{|c|c|c|c|c|c|c|c|c|c|c|c|}
\hline No & $\begin{array}{c}\text { Jenis } \\
\text { Kredit }\end{array}$ & $\mathbf{2 0 1 3}$ & $\mathbf{\%}$ & $\mathbf{2 0 1 4}$ & $\mathbf{\%}$ & $\mathbf{2 0 1 5}$ & $\mathbf{\%}$ & $\mathbf{2 0 1 6}$ & $\mathbf{\%}$ & $\mathbf{2 0 1 7}$ & $\mathbf{\%}$ \\
\hline 1 & Lancar & 430.405 & 89,42 & 466.619 & 90,20 & 514.407 & 89,21 & 607.490 & 93,53 & 817.655 & 95,51 \\
\hline 2 & $\begin{array}{c}\text { Kurang } \\
\text { Lancar }\end{array}$ & 17.150 & 3,56 & 22.343 & 4,32 & 26.355 & 4,57 & 16.929 & 2,61 & 20.543 & 2,39 \\
\hline 3 & Diragukan & 21.178 & 4,39 & 21.764 & 4,21 & 28.354 & 4,92 & 17.894 & 2,75 & 11.231 & 1,31 \\
\hline 4 & Macet & 12.601 & 2,62 & 6.541 & 6.541 & 1,26 & 7.154 & 1,30 & 7.189 & 1,11 & 0,77 \\
\hline & Jumlah & 481.334 & 100 & 517.267 & 100 & 576.630 & 100 & 649.502 & 100 & 856.079 & 100 \\
\hline & NPL & & 10,57 & & 9,79 & & 10,79 & & 6,47 & & 4,47 \\
\hline
\end{tabular}

Sumber: BPR Lubuk Raya Mandiri, 2019

Dari tabel diatas dapat dilihat tingkat kolektibilitas nasabah cendrung berfluktuasi, pada kategori lancar dari jumlah kolektibilitas sebanyak RP. 481.334 (tahun 2014) ternyata 89,42\% atau RP. 430.405 merupakan kredit lancar, dimana kredit bermasalah sebesar 10,57\% yang terdiri atas 3,56\% kredit kurang lancar, 4,39\% diragukan dan 2,62\% macet. Pada tahun 2015 kredit lancar sebesar 90,20\% atau RP. 466.619 dari jumlah jumlahkolektibilitasnya, penurunan NPL dari 10,57\% menjadi $9,79 \%$ disebabkan oleh peningkatan pedapat nasabah yang artinya kemampuan membayar nasabah juga meningkat. Pada tahun 2016 terjadin peningkatan NPL yaitu kredit lancar turun sebesar 89,21\% kredit kurang lancar naik 4,57\% kredit diragukan naik menjadi 4,92\% dan kredit macet 1,30\% dan artinya pada tahun 2016 ini terjadi peningkatan NPL yang cukup signifikan menjadi 10,79\% pada tahun 2017 dan 2018 terjadi penurunan kredit bermasalah hal ini disebabkan karana BPR Lubuk Raya Mandiri memperbaiki manajemennya dalam mengelola kredit bermasalah. Pada dasarnya kredit yang disalurkan oleh PT. BPR Lubuk Raya Mandiri cendrung lancar, walaupun masih ada kredit bermasalah.

\section{Penyebab Kredit Bermasalah}

Pnyebab terjadintya kredit bermasalah Pada PT. BPR Lubuk Raya Mandiri yaitu disebabkan oleh merosotnya perekonomian yang mengakibatkan kemampuan membayar angsuran pokok dan bunga pinjaman mengalami masalah sehingga lancar menjadi kurang lancar, diragukan bahkan macet.

\section{Penyelesaian Kredit Bermasalah}

Dalam penyelesaian kredit bermasalah bank mempunyai kebijakan dan strategi, dalam hal ini PT. BPR Lubuk Raya Mandiri menempuh langkah penyelesaian kredit bermasalah sebagai berikut:

a. Kredit Kurang lancar. 
Bagi kredit yang kurang lancar bank memberi teguran kepada pihak debitur lewat telfon, bahwa debitur sudah mulai menunggak kewajiban pembayaran kepada PT. BPR Lubuk Raya Mandiri.

b. Kredit Diragukan.

Untuk Kredit diragukan bank akan memberi surat peringatan kepada debitur, bahwa debitur mulai tidak memenuhi kewajibanya beberapa bulan terakhir kepada pihak PT. BPR Lubuk Raya Mandiri.

c. Kredit Macet

Jika semua surat peringatan kredit tidak bisa dilunasi oleh pihak debitur, maka bank tidak akan lagi memberikan surat peringatan apapun dan memlilih tindakan tegas yaitu berupa penyitaan asset jaminan kredit.

Dalam melaksanakan tindakan ini bank mengambil keputusan melelang jaminan debitur di depan umum agar melunasi tunggakan kewajiban debitur kepada bank. Dalam hasil penjualan disetorkan agunan akan disetorkan kepada bank untuk memperhitungkan dengan debitur, jika hasil penjualan itu berlebih maka dikembalikan lagi kepada debitur.

\section{SIMPULAN}

1. Pelaksanaan kredit di PT. BPR Lubuk Raya Mandiri cukup baik, terlihat dari kolektibilitas kredit lancar yang mengalami kenaikan dari tahun 2013-2017 dan kredit bermasalah mengalami penurunan.

2. Penyebab kredit bermasalah yang disebabkan oleh merosotnya perekonomian yang mengakibatkan kemampuan pembayaran angsuran pokok dan bunga pinjaman mengalami masalah sehingga lancar menjadi kurang lancar, diragukan bahkan macet.

3. Penyelesaian kredit bermasalah yang dilakukan PT. BPR Lubuk Raya Mandiri mempunyai kebijakan dalam penyelesaian kredit yaitu dengan cara bank akan memberikan teguran terlebih dahulu melalui telepon, jika tidak juga bank akan mengirim surut dengan bentuk surat peringatan kepada debitur, jika hal itu tidak diabaikan juga maka pihak bank akan mengambil keputusan akan melakukan penjualan agunan atau melelang agunan tersebut di depan umum agar dapat melunasi kewajiban debitur kepada bank.

\section{UCAPAN TERIMA KASIH}

Penulis mengucapkan terima kasih kepada:

1. Kedua orang tua yang senantiasa merawat dan mndidik serta mncurahkan kasi sayang pada penulis.

2. Direkur AKBP beserta prodi AKBP serta bapak ibuk dosen yang tela mendidik dan mmberikan ilmu pngetahuan kepada penulis.

3. Pemimpin PT. BPR Lubuk Raya Mandiri Padang yang telah mengizinkan penulis memperoleh informasi

4. Kepada semua piak yang telah membantu dalam membuat tugas akhir. 


\section{DAFTAR PUSTAKA}

Amelia, L., \& Marlius, D. (2018). Pengendalian Kredit Dalam Upaya Menciptakan Bank Yang Sehat Pada PT. Bank Pembangunan Daerah Sumatera Barat Cabang Utama Padang. https://doi.org/10.31227/osf.io/kpc64

Alanshari, F., \& Marlius, D. (2018). Prosedur Pemberian Kredit KPR Pada PT. Bank Tabungan Negara (Persero) TBK Cabang Pembantu Bukittinggi. https://doi.org/10.31227/osf.io/rsfhc

Baiya, \& Fernos, J. (2019). Analisis Faktor-Faktor Penyebab Kredit Macet Pada Bank Nagari Cabang Siteba. https://doi.org/10.31227/osf.io/4xuks

Bekti Krestianto, S. (2006). Pelaksanaan Penyelesaian Kredit Bermasalah Dengan Jaminan Hak Tanggung Di PT BANK RAKYAT INDONESIA (PERSERO) Tbk Cabang Semarang. 1-173.

Desda, M. M., \& Yurasti. (2019). Analisis Penerapan Manajemen Risiko Kredit Dalam Meminimalisir Kredit Bermasalah Pada PT. BPR Swadaya Anak Nagari Bandarejo Simpang Empat Periode 2013-2018. 18(1), 94-106. https://doi.org/10.33557/mbia.v18i1.351

Firmansyah, A., \& Fernos, J. (2019). Analisis Kredit Bermasalah Dilihat Dari Standar Non Performing Loan (NPL) Pada PT. Bank Perkreditan Rakyat (BPR) Prima Mulia Anugrah Cabang Padang. https://doi.org/10.31227/osf.io/gcj94

Febriansyah, I. (2019). Penyelesaian Kredit Bermasalah PT. Bank Pembangunan Daerah (BPD) Sumbar Cabang Alahan Panjang Kabupaten Solok Ilham Febriansyah , Afriyeni. Akademi Keuangan Dan Perbankan, 1-14. https://osf.io/preprints/vutmj/

Firmansyah, A., \& Fernos, J. (2015). Analisis Kredit Bermasalah Dilihat Dari Standar Non Performing Loan ( Npl ) Pada Pt . Bank Perkreditan Rakyat ( Bpr ) Prima Mulia. 1 of 13.

Ikbal, M., \& Marlius, D. (2017). Pengaruh Jumlah Taksiran Dan Uang Pinjaman Terhadap Laba Bersih Pada PT. Pegadaian (UPC) Gurun Laweh. https://doi.org/10.31227/osf.io/uch4a

Nazila, L., AR, M., \& Sudjana, N. (2016). ANALISIS PENYELESAIAN KREDIT BERMASALAH ATAS AGUNAN HARTA TIDAK BERGERAK (Studi pada PT Bank Mandiri Tbk. Unit Mikro Cabang Probolinggo Kraksaan). 35(1), 78-85.

Rosmilia, R. (2009). Pelaksanaan penyelesaian kredit bermasalah Studi PT. Bank Rakyat Indonesia (Persero) Tbk. cabang Semarang Pattimura.

Savitri, O. A., Z.A, Z., \& Nuzula, N. F. (2014). Kredit Bermasalah Pada Kredit Usaha Rakyat ( Studi pada Bank Jatim Cabang Mojokerto ). 12(1), 1-10.

Sulastri, L. (2015). Konstruksi Perlindungan Hukum Debitur Dalam Penyelesaian Kredit Bermasalah Dengan Pelaksanaan Lelang Jaminan Hak Tanggungan. 1(1), 86-101. https://doi.org/10.33603/hermeneutika.v1i1.1962

Tanzil, A. (2015). Penyelesaian Kredit Bermasalah Pada PT. BANK BTPN MUR Tbk. Cabang Solo. 151, 10-17. https://doi.org/10.1145/3132847.3132886 
Widayati, R. (2019). Penyelesaian Kredit Bermasalah Pada PT. Bank Perkreditan Rakyat (BPR) Nagari Kasang. https://doi.org/10.17605/OSF.IO/D4MF3

Widayati, R. (2019). Pelaksanaan Prinsip Kehati-Hatian Dalam Pemberian Kredit Konsumtif Pada Bank Nagari Cabang Siteba. https://doi.org/10.17605/OSF.IO/FZVXR

Widayati, R. (2019). Aktivitas Pemberian Kredit Komersil Pada Bank Nagari Cabang Sijunjung. https://doi.org/10.17605/OSF.IO/QTVZ9

Widayati, R. (2019). Pelaksanaan Kredit Pada Bank Perkreditan Rakyat LPN Pasar Baru Durian Sawahlunto. https://doi.org/10.17605/OSF.IO/5HPAB

Widayati, R. (2019). Upaya Penanganan Kredit Bermasalah Pada Bank Nagari Cabang Utama Padang. https://doi.org/10.17605/OSF.IO/YJ3KN

Widayati, R. (2019). Aktivitas Pemberian Kredit Usaha Pada PT. Bank Perkreditan Rakyat Batang Kapas. https://doi.org/10.17605/OSF.IO/EDPN4 